\title{
REDUCING THE ADHESION FORCE OF THE WHEELS OF THE ROAD VEHICLES
}

\author{
P. Jilek*, I. Šefčík ${ }^{* *}$, J. Verner***
}

\begin{abstract}
The article deals with influence of the controlled adhesion force in the contact between a wheel of a road vehicle and a road. In the first section, a way to reach a decrease of adhesion force is presented. Then follows description of the experimental vehicle, which experimental measurements were realized on. The mutual assessment of the advantages and disadvantages of the both experimental test methods is presented next. The purpose of the article is to discover difference between vehicle's behavior when the adhesion force is influenced by the change of the reaction force and by the change of the adhesion coefficient.
\end{abstract}

Keywords: road vehicle, adhesion, tyres, adhesor, car testing.

\section{Introduction}

Currently, autonomous road vehicles increasingly come to the fore. From this point of view, it's necessary to ensure that these vehicles meet safety requirements. And so new vehicles are still being equipped with new electronic assistants. To increase car stability an experimental vehicle with a $4 \mathrm{WS}$ system was realised at Department of Transport Means and Diagnostics. Just this attribute is supposed to be used to increase the vehicle's stability when driving on a skid's verge.

We order to bring the car to the skid's verge while driving safely it's possible to realise the experimental measurement either on a slide surface or with the aid of the SkidCar device. Currently, there are no suitable areas to use slide surfaces and therefore we used the SkidCar device.

\section{Methods}

\subsection{System SkidCar}

The SkidCar system was produced by Cedergrens Klintehamn in Sweden. Essentially, it was an electrohydraulic wheel chassis that enables the moving vehicle to reach various types of adhesion conditions (Jörnsen, 2001). The chassis was fixed to the vehicle's ground and thanks to an electronically controlled hydraulic circuit it enables reducing the load on the front axle, rear axle or both axles simultaneously, in any extent. With closer familiarisation with offered chassis, we discovered that it's only possible to use SkidCar with selected vehicles. Therefore, we proceeded to design a frame for the experimental vehicle. As we made changes on the frame compared to a commercially available system, we use the name alternative SkidCar. The main difference was in the mechanical way of radial reaction change on the vehicle's wheels. We also placed the front wheels of the alternative SkidCar behind the front axle's axis, as shown in (Fig. 1). This is how we achieved that the body clones more easily than the commercial $\mathrm{SC}$.

\footnotetext{
* Ing. Petr Jilek, Ph.D.: Institute Faculty of Transport Engineering, University of Pardubice; Studentská 95; 53210 Pardubice; CZ, petr.jilek@upce.cz

** Ing. Ivo Šefč́́k, Ph.D.: Institute Faculty of Transport Engineering, University of Pardubice; Studentská 95; 53210 Pardubice; CZ,ivo.sefcik@upce.cz

*** Ing. Jan Verner.: Institute Faculty of Transport Engineering, University of Pardubice; Studentská 95; 53210 Pardubice; CZ, st31728@upce.cz
} 


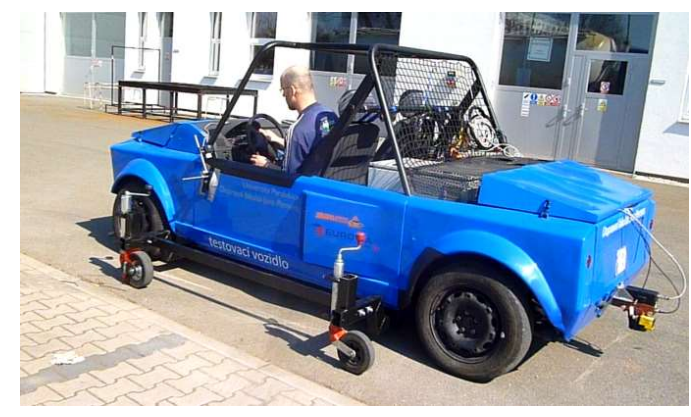

Fig. 1: Alternative SkidCar.

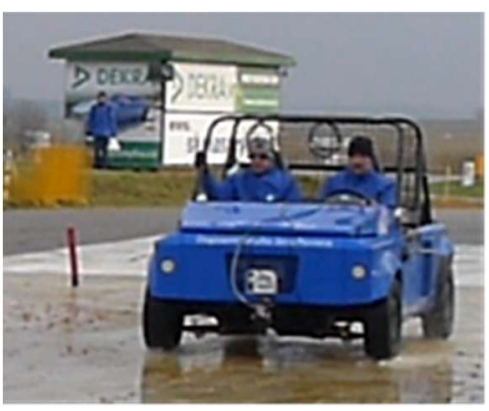

Fig. 2: Slide surface.

Strengths:

- the possibility of changing adhesion conditions while driving,

- keeps the car electronic systems active,

- a road bears no optical or other information on the change of adhesion conditions,

- can be used in vehicles with front, rear or with both driving axles,

- almost impossible to overturn a car,

- possible to use any tyres,

- ensures repeatability of adhesive conditions in different tests.

Weaknesses:

- a vehicle has auxiliary wheels on the sides - a larger width of the tested car is a negative feature while doing driving manoeuvres,

- a car body attached to the SkidCar frame - not possible to tilt the sprung masses against the unsprung masses; the body doesn't tilt or incline while doing driving manoeuvres,

- an electrohydraulic unit operation and electromagnets is heard in the vehicle; a driver is notified of a change in adhesion conditions,

- increasing a car mass and reducing the elevation coordinates of a car's centre of gravity,

- a need for a relatively flat surface of sufficient size under the considered testing.

We stated stiffness of supporting wheel units at the static adhezor (Krmela, 2008 and Krmela at al., 2014), which was a property of Department of Transport Means and Diagnostics. The way of acquiring of the characteristic evident in (Fig. 3). The deformation characteristic is in (Fig. 4) and described by the equation (1) with confidence $R$.

$$
y=-0,3441 x^{2}+5,8352 x ; \quad R^{2}=0,9996
$$

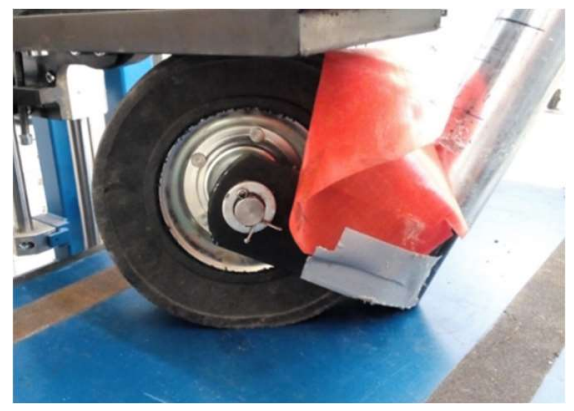

Fig. 3: Deformation characteristic discovery.

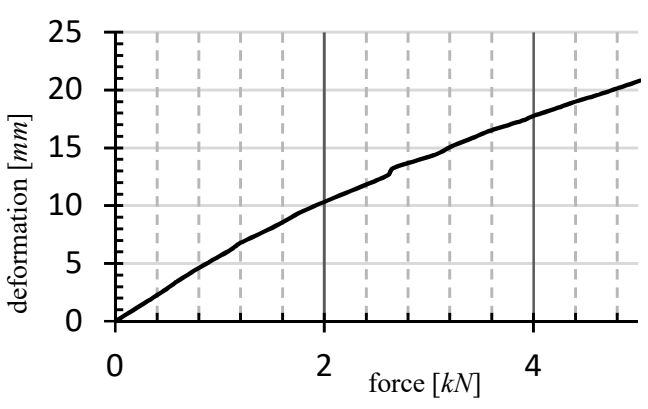

Fig. 4: Deformation characteristic.

\subsection{Drive test}

We chose the slalom test like a driving test. The test's purpose was that the vehicle drives through marked out corridor between cones with predefined velocity. We chose the maximal velocity for the car to be able to go through the marked out corridor on a slippery surface. The driving corridor arrangement for the alternative SkidCar's experimental test is shown in (Fig. 5), for slippery surface in (Fig. 5). 
Where $t_{6}$ - distance between cones, $t^{\prime}{ }_{7}-$ offset of SkidCar's cones, $K$-cone. We proposed the driving test with $50 \%$ radial reaction on the vehicle's wheels.

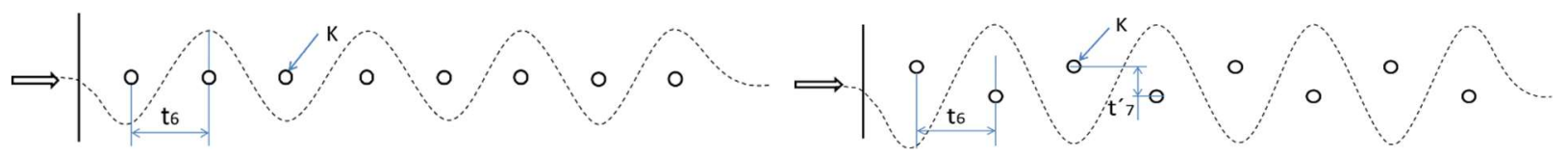

Fig. 5: Corridor for slalom test for slide surface and the alternative SkidCar.

\subsection{Measured quantities}

We measured velocity $v$, deviation angle $\varphi$ and vehicle's yaw velocity $\omega$ (Marek et al., 2016) with the Correvit sensor. We discovered steering angle $\beta_{v}$ via analog string position sensor. Transverse $a_{y}$ and longitudinal $a_{x}$ acceleration using accelerometer and bodywork's tilt angle $\beta_{i}$ using a couple of ultrasonic distance sensors placed in the centre of gravity plane by the sides of the vehicle.

We calculated the bodywork's tilt angle by equation (2), where $H_{3 i}\left(H_{4 i}\right)$ is the distance between measurement place at the fore (aft) of the bodywork and the road in the time $t_{i}, B_{x}$ is mutual distance of measurement points in the transversal plane of the vehicle, $H_{30}\left(H_{40}\right)$ is the distance of the measurement point appropriate with stabilized vehicle's motion velocity.

$$
\beta_{i}=\tan ^{-1}\left(\frac{\left(H_{3 i}-H_{3 o}\right)-\left(H_{4 i}-H_{4 o}\right)}{B_{x}}\right)
$$

It was compared measured outcomes to the experimental measurement on a slide surface.

\section{Evaluation of the measured courses}

Courses of velocity $v$, longitudinal acceleration $a_{x}$ and transversal acceleration $a_{y}$ are comparable in both tests together with the steering angle $\beta_{v}$. There is an apparent difference in the course of the height position of the lower right axle arm HL1, where the alternative SkidCar's stroke is significantly influenced by using a framework (Fig. 6). Similar influence of the bodywork's tilt is apparent with the alternative SkidCar in both courses $H L 2$ and $H P 2$. The difference in bodywork's tilt angle corresponds with the data measured by height sensors and that proves, that the alternative SkidCar bodywork's tilt is negligible in comparison to the experimental vehicle (Fig. 6). This is the most significant difference in the measured courses.
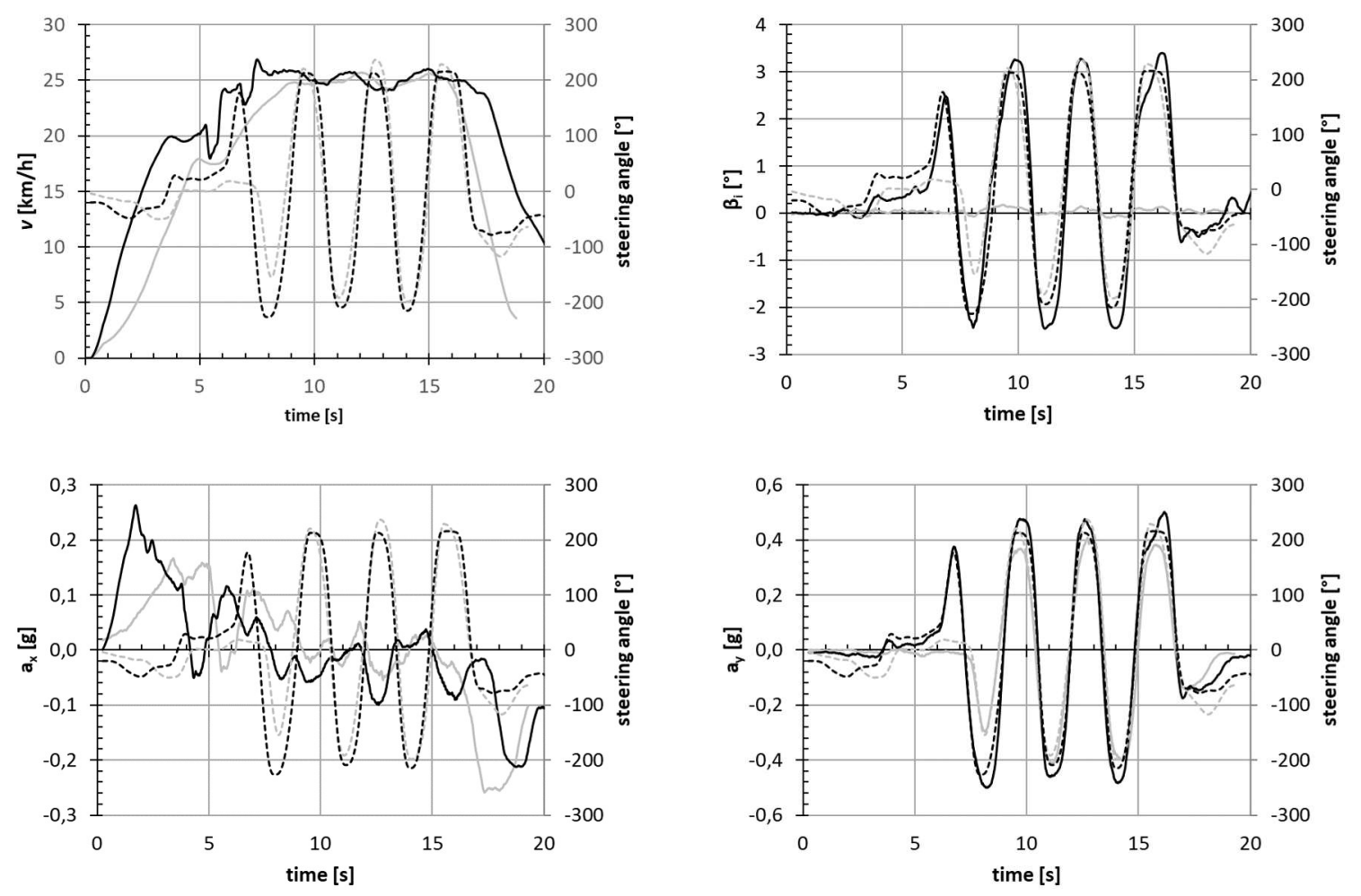

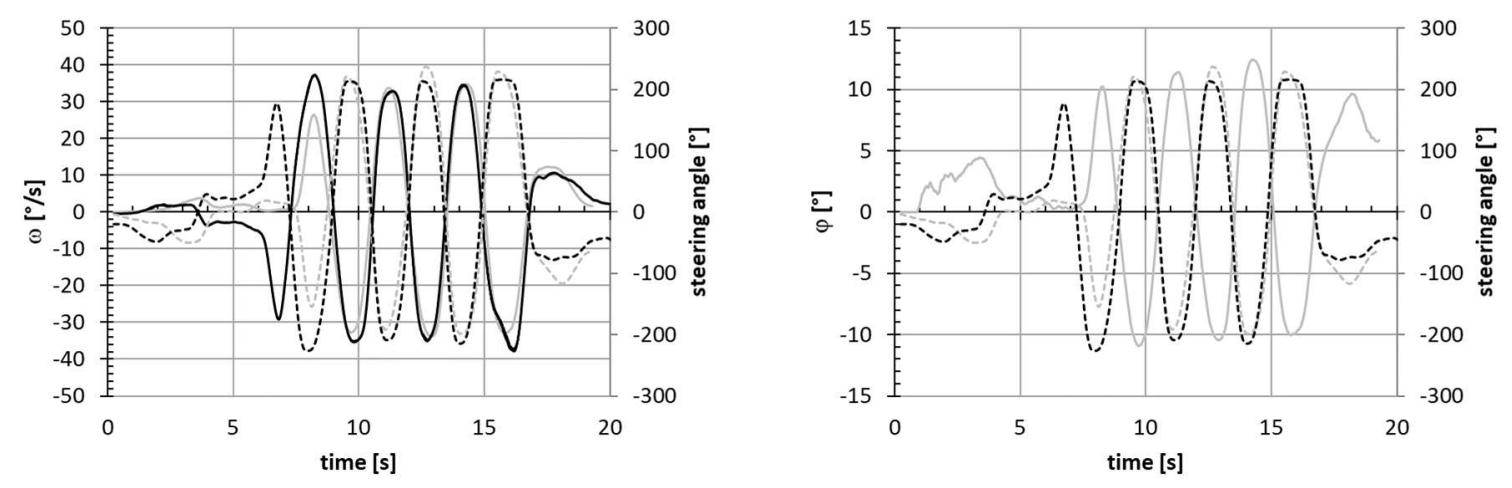

- SkidCar, --- steering angle, _Experimental vehicle slide surface, --- steering angle

Fig. 6: Measured characteristics.

The change in longitudinal acceleration ax was caused by driver's effort to maintain constant velocity at all times during the driving test. The sense of steering velocity $\omega$ and the deviation angle $\varphi$ were against the steering angle in the opposite phase. This was caused by the sense of placing the Credit sensor on the vehicle. The courses of both previously mentioned are mutually comparable and correspond to the theoretical base.

The difference in the alternative SkidCar bodywork's tilt angle was caused by the way it was attached to the vehicle's bodywork. We recommend reducing the weight of the unsprung masses for the bodywork's tilt optimisation and to simultaneously minimise added mass.

Simultaneously decreasing the vehicle wheels' radial reaction by $50 \%$ doesn't correspond with the $50 \%$ adhesion coefficient reduction. The reason was that vehicle wheels' radial reaction decrease is followed by camber change and so wheels roll with different side incline. Therefore the wheels slip easier on the road. The stated issues will the object of further research.

\section{Conclusions}

It's evident in measured courses, that the alternative SkidCar system enables changes in the adhesion force transmitted between the road vehicle's wheel and the road. Concerning the steering velocity and the deviation angle, the courses of these quantities are very similar. Distinct difference is on bodywork's tilt (Fig. 6).

Considering measured data, each interference to road vehicle's chassis system construction has, in the end, greater or smaller influence on the vehicle's behaviour. And so the alternative SkidCar system also influences the car's behaviour.

\section{References}

Jörnsen, R., Helmut, S. (2001) The automotive chassis engineering principles: chassis and vehicle overall, wheel suspensions and types of drive, axle kinematics and elastokinematics, steering, springing, tyres, construction and calculations advice. 2nd ed. Oxford, Butterworth Heinemann. ISBN 07-506-5054-0.

Krmela, J. (2008) Computational modelling of tyres considering operating and safety requirements. Communications. Scientific Letters of the University of Žilina. Žilina. ISSN 1335-4205.

Krmela, J., Beneš, L., Krmelová, V. (2014) Tire experiments on static adhesor for obtaining the radial stiffness value. Period. Polytech. Transp. Eng. Budapest, University of Technology and Economics. ISSN 1587-3811.

Marek, V., Čupera, J. (2016) Data Mining of Vehicle Control Units. In MendelNet: Proceedings of International PhD Students Conference. 1. vyd. Brno: Mendelova univerzita v Brně, 2016, s. 944--948. ISBN 978-80-7509-443-8.

Zdeněk, J., Žd’ánský, B., Čupera, J. (2008) Automobily I Podvozky. 1. vyd. Brno: Avid spol. s r.o. Brno, 228 s. ISBN 978-80-87143-03-2. 